\title{
Health Promotion in Ecuador: A Solution for a Failing System
}

\author{
Dana Rasch1, Krista Bywater ${ }^{2}$ \\ ${ }^{1}$ Richard Stockton College of New Jersey, Galloway, USA \\ ${ }^{2}$ Muhlenberg College, Allentown, USA \\ Email: dana.rasch@stockton.edu, kbywater@muhlenberg.edu
}

Received 25 February 2014; revised 27 March 2014; accepted 6 April 2014

Copyright (C) 2014 by authors and Scientific Research Publishing Inc.

This work is licensed under the Creative Commons Attribution International License (CC BY). http://creativecommons.org/licenses/by/4.0/

(c) (i) Open Access

\begin{abstract}
In 2008, the newly written Ecuadorian Constitution guaranteed access to healthcare for all citizens. Consequently, a vast amount of resources have been directed toward rebuilding the public healthcare system, which was in shambles due to the effects of neoliberalism. Although national healthcare studies show positive outcomes, community-based research studies from an impoverished rural barrio in southern Ecuador indicate that the public healthcare system has been unable to address a health epidemic. Based on several years of fieldwork, we argue that the failure originates from the continued functioning of the biomedical model of healthcare as the dominant health discourse in Ecuador. The ensuing result has been the construction of health system governed by an "administrative state" that enforces health policies from the top-down and delivers "episodic" emergency-style care. Accordingly, we maintain that the Ministry of Health (MOH) should create a nationwide community-based health promoter program guided by the principles of health promotion.
\end{abstract}

\section{Keywords}

Public Health, Latin America, Biomedicine, Health Promotion

\section{Introduction}

Since winning the presidency in 2006, President Correa and his political allies have been at the forefront of a so-called "citizens' revolution" in Ecuador. The ultimate objective of the movement is to develop a society where all citizens can live the "good life" through unimpeded access to important institutions such as the economy and healthcare [1] [2]. Consequently, one of the main foci of the Correa-led revolution is to create a healthcare system that will provide access to high quality services at no cost to not only Ecuadorians but anyone 
who steps foot in the country regardless of citizenship status. To accomplish this objective, the State Constitution was rewritten in 2008 to provide the government with the necessary legal authority to reinvent key institutions including the healthcare system [3]. However, President Correa and his political allies have faced a monumental task as they inherited a weak and ineffective healthcare system due to the failure of the neoliberal movement in Ecuador [4] [5]. To correct the free-market catastrophe, the Ecuadorian government has taken control of the healthcare sphere and the Ministry of Health $(\mathrm{MOH})$ is now one of the primary entities responsible for developing a universal public healthcare system.

Over the past several years, the MOH has been quite busy increasing the public health presence throughout Ecuador via the expansion of infrastructure and personnel along with developing state-led intervention programs to address serious healthcare problems. The initial results, at the national level, are nothing short of spectacular. Access to healthcare for the general population has increased considerably and intervention programs have had high levels of success even in the poorest regions of the country [6]-[8]. Beyond these national figures few studies examine the healthcare system at other levels, particularly the community level. In order to fill that gap, the authors teamed up with the residents of Las Mercedes, which is a rural and poverty-stricken barrio located on the coast of southern Ecuador, to assess the state of health in the community in both 2009 and, once again, in May of 2013. The results revealed that the services provided by the public health system are of low-quality. Furthermore, the system is unable to curtail the spread of infectious diseases such as malaria and dengue fever in Las Mercedes.

Drawing on fieldwork, we argue that the problems with the public health system can be traced to the continued functioning of the biomedical model of healthcare as the prevailing health narrative in Ecuador. Despite government efforts to include health promotion and prevention as part of the national plan, the unrelenting dominance of the biomedical framework has resulted in the building of a public health system that is governed by an authoritarian administration whose primary focus is to provide "episodic" emergency-style care. Accordingly, we maintain that the Ecuadorian healthcare system should implement a nationwide community-based health promoter program based on the principles of health promotion and preventive care in order to build a healthcare system that is able to effectively address infectious diseases at the community level while simultaneously providing high quality health services.

\section{The Ecuadorian Public Healthcare System}

Ecuadorian President Rafael Correa has embarked on a mission to build a country where all citizens are able to experience "buen vivir"-living well [2]. A major element to providing the "good life" is to deliver free, high quality, public healthcare for all citizens as mandated by the 2008 Constitution [9]. Reaching that goal has been exceptionally difficult due to the unraveling of the healthcare system over the previous decades. The destruction of Ecuador's healthcare system began in the early 1980's when Ecuadorian leaders bought into the ideas of neoliberalism being pushed by the Washington consensus in an attempt to reverse their failing economy. As part of the neoliberal reforms, government funding for the public healthcare system was slashed in order to rely on the "free market" to bring low-cost, efficient, and quality health care to everyone [10]. As dictated by the tenets of neoliberalism, the government's role was reduced significantly and funds from the public coffers were largely directed toward increasing the efficiency of clinical services in hospitals and other facilities [5]. What followed was years of disinvestment in the public healthcare system on behalf of the government, and by 2005, spending in Ecuador was one of the lowest in Latin America [11].

The privatization movement also provided fertile ground for the entrenchment of the biomedical model as the dominant mode of intervention to address health problems in Ecuador, particularly in the coastal region of the country where opposition to neoliberal policies was much less extensive than in the Highlands where indigenous uprisings were quite common [12]-[14]. The biomedical model posits that disease originates from "cellular abnormalities" due to individual pathology [15]. Healthcare systems that operate under this assumption, such as the neoliberal dominated one in Ecuador, rely heavily on highly trained physicians armed with an array of medications to cure individual patients. Health interventions and programs designed to promote good health and prevent disease, particularly ones that are community-based and led by non-medical professionals, are simply seen as unnecessary [14]. As Navarro [16] astutely points out, the biomedical framework is a perfect fit for privatized healthcare systems since it provides the opportunity for private physicians, hospitals, and clinics along with pharmaceutical corporations to turn enormous profits as they take the lead role in addressing all healthcare 
related issues. Although profit-oriented businesses might have benefitted from this approach to healthcare, Ecuadorians suffered immensely as the neoliberal experiment was a miserable failure. With privatization and the biomedical model as the foundation, not only was the public system in Ecuador in complete ruin but private healthcare was incredibly fragmented, pricey, and inaccessible for the majority of the population by the time Correa won the presidency in 2006 [4] [17]. Ecuadorians, as well, were suffering from a variety of health epidemics including over 100,000 cases of malaria in the 1990's [18].

To rebuild the healthcare system, the Ecuadorian government eliminated neoliberal policies and designated the Ministry of Health (MOH) as the primary entity responsible for reshaping the field. Public funding for the MOH has increased significantly since 2006 including a hefty \$1.6 billion USD in 2011. A large portion of those monies have been dedicated to expanding infrastructure in order to increase access to health services by purchasing private facilities, building public hospitals, and recruiting physicians who left the country due to the miserable state of the system [19]. Funding is only one aspect of the significant changes that are taking place. The return of healthcare to the public sphere has also resulted in a fundamental shift in the manner in which health problems are being addressed. The general approach of the government and the MOH is based on the tenets of "social medicine", which moves beyond the limited scope of the biomedical model and posits that social, economic, and political conditions are important contributing factors to widespread disease. For the past several years, the MOH has attempted to implement a multi-faceted model to resolving healthcare issues by not only recognizing the importance of the biomedical model in the form of medicine, science, and research, but also by putting substantial emphasis on addressing the negative environmental conditions are linked to the presence of disease and illness. For instance, the Ecuadorian government has installed sewage systems across the country with the aim of reducing the spread of communicable diseases [20]. The MOH has also developed a number of state-led intervention programs in high-risk, poverty-stricken communities to confront a variety of health related problems including teen pregnancy and tobacco use.

The increased funding along with an emphasis on addressing the social determinants of disease has resulted in remarkable achievements at the national level. First and foremost, access to health services has increased dramatically. A recent study revealed that 38 million patients received medical treatment in 2012, compared to only 16 million in 2006- the year that Correa won his first presidential election [8]. This high level of production resulted in Ecuador being named as the 20th most efficient healthcare system in the world ranking higher than fellow socialist countries Venezuela and Cuba [21]. Other statistics released by the national government are also promising including a sharp reduction in the infant mortality rate and a staggering twenty-one percent reduction in the rate of anemia for children under the age of five in just one single year-2010-11 [6].

\section{A Community-Based Response to a Healthcare Crisis}

Beyond the national level, few research studies have analyzed healthcare at the community level in Ecuador. The purpose of this manuscript is to fill that gap in the literature by providing a community-level analysis based on fieldwork and research carried out in the rural community of Las Mercedes, which is located on the outskirts of the City of Huaquillas on the coast of southern Ecuador. Las Mercedes originated as an "invasion" barrio as squatters moved to the area in order to work in the garbage dump located in the northeast corner of the impoverished town. In 1992, the city government recognized Las Mercedes as an official community; however, very few of the approximately 400 families that reside in the barrio possess the legal title to their land. Of particular importance, the vast majority of persons who live in Las Mercedes and in the City of Huaquillas, identify as "mestizo," which indicates that they are racially and culturally "mixed" with usually a combination of European and indigenous heritage. Although indigenous traditions are still practiced in various forms, few indigenous approaches are used in the realm of healthcare. Western-style medicine that emphasizes the "expertise" of medical professionals and the use of drug regiments to cure disease is preferred by the vast majority of persons in Las Mercedes and the surrounding areas [12].

In 2009, a community-based needs assessment was completed in Las Mercedes. Participatory Action Research (PAR) was employed to insure that community members were in control of the research process from start to finish. PAR differs from traditional positivist-oriented research methods since it requires researchers to act as facilitators to community members who are working collaboratively "to understand and improve the world by changing it" [22]. The research participants included the first author, a youth group with approximately 15 members from Las Mercedes, and several representatives from a national non-governmental organization 
(NGO) that operated in the City of Huaquillas. The goal of the assessment was to collect and analyze data in order to identify problems in the community and develop a community-led project to solve the most pressing social issue.

In order to capture the varying views and perspectives of residents, the participating groups developed a set of interview questions over several meetings and discussions. After an interview guide was finalized, the first author trained the youth group members to conduct door-to-door interviews. Over the course of several months, the youth group, under the guidance of the first author, completed over 100 interviews with heads of households in Las Mercedes. To insure a fair representation of the community every 4th house was selected to participate in the research study. If no one was home, the team returned to the house at a later date to complete the interview. If the house was vacant, they simply moved to the next occupied house. Interviews were carried out in teams of 2 - 3 youth group members with one member designated as the "scribe" in order to annotate responses. The interviews lasted anywhere between 20 - 45 minutes.

The interviews focused on several important problem areas such as the economy, education, and health care. Healthcare related inquiries included questions about the quality of healthcare services, the heath needs of each households, and the self-reporting of disease and illness. The data from the interviews was compiled and analyzed by the youth group with the first author acting as a facilitator in an ongoing process that involved discussion and dialogue. Much of the analysis revolved around the findings related to the health of the community as youth group members were shocked by the data in this area. A crucial finding was that $56 \%$ of families self-reported that a family member suffered from an infectious disease including malaria and dengue within the past year. In the end, the group identified healthcare as the most pressing problem in Las Mercedes and everyone agreed that the community must take action in order to resolve the problem.

Based on the ideas that emerged from the assessment, adult residents created a community-based disease prevention program in the spring of 2010 with community members volunteering to work as health promoters. The objective of the health promotion program was simple: to work collaboratively with the MOH to carry out prevention efforts in order to reduce the rate of infectious diseases such as malaria and dengue fever in Las Mercedes. To begin the program, volunteers participated in a year-long training course that was led by local doctors from the government. Since the $\mathrm{MOH}$ has no procedures in place to train community members, the physicians worked outside of the bounds of the system and participated on a voluntary basis. The curriculum of the training course was driven by the healthcare needs identified in 2009 community-based survey as well as based on an ongoing dialogue between the doctors and the community trainees. The training preparation encompassed a variety of themes including the prevention of dengue and malaria at the community level.

To finalize the program, the trainees completed an extensive community-based health research study in 2011 by surveying 244 families. The future health promoters gathered data on a variety of health related topics including hygiene habits, living conditions, and the overall state of health. The data was analyzed and used to develop a community disease prevention plan that included a variety of activities such as door-to-door malaria testing, educational workshops, and organizing work parties to clean public spaces of debris and standing water. For approximately one year activities were carried out by the health promoters, however, the program ultimately failed. Much of this failure has been attributed to the lack of governmental support after the doctors who led the program were transferred to another region. Since the program was outside of the normal bounds of the public healthcare system, the lack of access to medical resources, local doctors, and other materials, led to the program being considered unsustainable by participants in summer of 2012.

\section{Reassessing Healthcare in Las Mercedes}

One year after the demise of the program, May of 2013, a community-based survey using PAR was completed by a team of local residents-approximately 15 adult men and women-in Las Mercedes to reassess the state of healthcare in their community. The general aim of the survey was to gauge the level of access to quality health services as well as the prevalence of infectious diseases in the community. The research team decided that the most effective way to gather data would be through the application of a door-to-door survey questionnaire. The questions for the survey were developed through a number of discussions facilitated by the authors. After creating the survey, the research team received training from the authors on how to conduct survey questionnaire interviews. The team proceeded to apply the survey questionnaire via door-to-door interviews working in pairs in order to provide support and assistance to one another. Every fourth house was selected to participate in the 
survey resulting in 108 heads of households (approximately 27.8\% of all households in Las Mercedes) participating in the study. To analyze the data, several meetings were conducted in the community center with the interview team in order to review surveys, identify patterns, and discuss the most prevalent problems. The meetings were facilitated by the authors and normally lasted anywhere between two to three hours. In addition to the general discussions, basic descriptive statistics were tabulated for relevant questions and to paint an overall picture of the situation.

\section{Results}

According to the analysis carried out by residents and facilitated by the authors, the survey data revealed three important patterns. First, the vast majority of residents, $92.6 \%$, utilize the public healthcare system as their primary provider. This finding is not surprising considering that the poverty-stricken state of the community as families are all but forced to use the public healthcare system due to an inability to pay for a private doctor. Second, although the majority of residents utilize the public healthcare system, only $11 \%$ of heads of households responded positively when asked about the quality of services rendered. $38 \%$ of responses were categorized as negative with common adjectives being used such as "terrible" and "bad" to describe the public healthcare services. When prodded to elaborate by survey interviewers, respondents cited a laundry list of problems including long lines, a lack of medicine, and poor attention from medical personnel. Third, infectious diseases continue to be prevalent in the community. Of the 108 households surveyed, there were 26 cases of dengue fever and 27 cases of malaria self-reported in the past year.

\section{The Biomedical Model and the Failing Ecuadorian Health System}

The results from the community of Las Mercedes reveal a much different picture of the healthcare system than the rosy one painted by national figures. As indicated by the residents, the quality of healthcare services being provided by the public health system is abysmal. Even more alarming, infectious diseases such as malaria and dengue fever continue to run rampant in the community. One might immediately assume that the public healthcare system is lacking funding, but as previously discussed this is not the case as billions of dollars are being spent annually by the well-intended government. Our fieldwork reveals that the failure of the public healthcare system is not a matter of money, but the fact that the biomedical model continues to function as the dominant health discourse within the healthcare realm, particularly in areas with a small indigenous population such as Las Mercedes.

The biomedical model of healthcare is "characterized by scientific medicine employing clinical diagnostic and treatment processes within the context of the physician-patient relationship” [23] [25]. Essentially, the focus of attention is on treatment and repair of the individual rather than understanding the origination of the disease in its totality and using models that aim to prevent disease [15]. With the biomedical model as the philosophical foundation, the public health system in Ecuador has become engrossed in providing "episodic" care to curtail healthcare crises across the country such as the one in Las Mercedes. Episodic care is similar to medical attention provided in an emergency room where patients are treated by medical professionals for a particular problem in order to save lives and ease suffering as quickly as possible. With episodic care as the primary focus, the $\mathrm{MOH}$ concentrates principally on increasing the productivity and efficiency of the system. Commonly referred to as "throughput" in the field of healthcare, the idea is to use resources and various techniques to maximize proficiency in order to increase patient numbers, minimize wait times, and reduce overcrowding. The approach has been incredibly successful for Ecuador in terms of increased access to the healthcare system as evidenced by the 38 million patients who received medical attention in 2012 [8]. However, the increased efficiency has not resulted in high quality services being provided or a reduction in infectious diseases in Las Mercedes as shown by the research in this manuscript.

In most cases, reliance on the biomedical model and episodic care also results in a lack of resources directed toward preventive efforts since the holistic nature of disease and illness is ignored. In accordance with their mission and vision that relies on the basic tenets of social medicine, the MOH has developed a number of programs and projects to address the social, economic, and cultural influences that cause disease and illness. In contrast to the reactive character of the biomedical model, these state-led programs aim to prevent chronic disease. For example, in Ecuador 22 out of 100 children under the age of five suffer from chronic malnutrition. To address this health problem, the MOH developed “Acción Nutrición: Hacia La Desnutrición Cero" (Nutrition Action: 
Toward Zero Malnutrition), which is an intervention to reduce child malnutrition and anemia. The program includes house visits from child development specialists and doctors, and the distribution of various snacks that are fortified with essential vitamins and minerals. National figures have shown impressive results from the intervention program including a 10\% reduction in the rate of malnutrition in Manabí, one of the poorest regions on the coast of Ecuador [6].

The results from the state-led prevention programs are remarkable. Nevertheless, these programs also fall prey to the limits of the biomedical model. Interventions are developed, administered, and overseen by MOH administrators as dictated by the biomedical paradigm, which posits that only physicians, researchers, and other experts possess the training and know-how to solve health problems. As health interventions are carried out in communities such as Las Mercedes by "outside experts", the importance of the medical professional is reinforced and reproduced. Communities are simultaneously disempowered since they are unable to make any meaningful contributions to address health problems in their own community. The manner in which these interventions are carried out is a mere representation of the regular institutional practices of the $\mathrm{MOH}$ that cement the idea that residents are not a part of the solution but the source of the problem. Ultimately, the MOH can be characterized as an "administrative state," which is an organization that develops and enforces policies from the top-down and is hierarchically governed by a vast number of highly trained and appointed, not elected, officials [25] [26]. The administrative state is undemocratic and authoritarian as decision-making processes involve only the "expert" administrators and no channels or avenues exist for citizen participation. Consequently, as our fieldwork in Las Mercedes indicates, community-based programs that involve extensive participation on behalf of residents find it difficult to operate and survive in a field where the most powerful organization is governed in this top-down manner. The lack of government support is detrimental to these community-based programs as residents are left alone on an island struggling to pull together the small amount of resources available in the community.

In 2010, the Director of the MOH, Dr. David Chiriboga, was blamed for the continued failure of Ecuador's health system and ultimately replaced. However, our analysis suggests that the failure of the MOH to deliver quality healthcare, address ongoing health epidemics, and prevent future outbreaks extends well beyond one single individual and is profoundly connected to the biomedical model functioning as the dominant narrative within the system [24]. Despite the increased funding and vision of the Ministry of Health, the supremacy of the biomedical framework has resulted in the development of a powerful administrative state that delivers episodic care to a population that has become increasingly dependent on Western-style solutions to healthcare problems carried out by the government. Furthermore, intervention programs that aim to solve key healthcare problems are not community-oriented but directed from above resulting in a lack of meaningful participation by local residents. The outcome has been disastrous for communities confronting a health crisis such as the one in Las Mercedes. In the end, residents simply wait idly by for medical professionals from the $\mathrm{MOH}$ to address the health epidemic in their community. Unfortunately, although outcomes at the national level are positive, communities such as Las Mercedes are continuing to suffer due to this approach.

\section{A National Supported Community-Based Health Promoter Program}

The World Health Organization (WHO) defines health promotion as "the process of enabling people to increase control over their health and its determinants, and thereby improve their health" [27]. The model as a mode of health intervention necessitates extensive participation on behalf of community members in order to put into action locally run programs that address health problems such as the threat of malaria and dengue fever in Las Mercedes. With community members intimately involved in developing and executing health interventions, the model is in direct opposition to the biomedical framework, which relies solely on medical professionals. The health promotion model allows residents to work together in a collaborative fashion with other organizations, which can include the local government, health ministries, and other entities, to resolve health issues in their communities. Furthermore, the health promotion model doesn't rely on the magic of medicine, but moves toward the principles of social medicine by recognizing that environmental factors such as the living conditions, political atmosphere, and culture of a community play an important role in causing disease and illness. Ultimately, this orientation requires that intervention programs address health problems on a number of different levels through a collaborative process that involves widespread participation by community members. The general idea, contrary to the reactive nature of the biomedical model, is to prevent disease and illness through coordi- 
nated and collaborative efforts in support of building a healthy community.

Although health promotion is not anything novel in the field of healthcare, the popularity of the model has risen considerably in the past few years. Indeed, the most prominent healthcare institution in the world, the WHO, directs an international program to encourage the spread of the health promotion framework across the globe. The increased use of health promotion stems from the extensive amount of research that has revealed its effectiveness in preventing disease and building healthy communities, particularly in so-called "third world" countries due to the cost-effective nature of the model [28]. Kumar and Preetha [29] argue that "health issues can be effectively addressed by adopting a holistic approach by empowering individuals and communities to take action for their health, fostering leadership for public health, promoting intersectoral action to build healthy public policies in all sectors and creating sustainable health systems". In particular, community-based intervention programs aimed at reducing communicable diseases such as HIV, malaria, and dengue have been highly successful in developing countries [29] [30].

As we have discussed, the general philosophy of the MOH is geared toward social medicine, health promotion, and prevention; however, implementation of this approach has been overshadowed and guided by the biomedical framework. The result is the development of a system unable to resolve problems in poverty-stricken communities such as Las Mercedes. For these reasons, we maintain that the Ecuadorian MOH should develop a nation-wide community-based health promoter program that not only stresses health promotion and prevention, but also the importance of community participation. Instead of disempowering communities similar to current interventions, the program would allow the government to work collaboratively with local residents in communities throughout Ecuador in order to understand, address, and solve health problems at the community level. Indeed, collaborative programs rooted in health promotion and disease prevention have been shown to be highly productive in addressing health problems such as the ones faced in Las Mercedes [31]. In a practical sense, the program can operate similar to the previous one in Las Mercedes with the $\mathrm{MOH}$ recruiting and training residents to serve as health promoters in their own communities. Training programs would be led by local doctors from the $\mathrm{MOH}$, but each course of study should be tailored to the needs of the community itself and the initial group of volunteer trainees should identify the most pressing needs in order to develop the training agenda. The inclusion of a health-based needs assessment as the final phase of the training program is also crucial for developing a strategy for the team of health promoters that will work collaboratively with fellow residents and their local public health officials. As revealed by our fieldwork in Las Mercedes, government support and collaboration is absolutely crucial to the sustainability and success of community-led programs. Therefore, the health promoters would need to receive continual training, support, and supplies from the MOH. However, to insure sustainability and community control, reliance on the government should be slowly minimized as the community builds its capacity to take greater responsibility and action carrying out healthcare plans [32].

Within each community, health posts should be established and directed by health promoters and provide a base to maintain files, equipment, and basic medicine. Although undertakings will vary from community to community based on need, health promoters can carry out a wide variety of disease prevention activities. For example, health promoters can conduct regular house visits in a door-to-door fashion in order to monitor the conditions and health of the community as well as at-risk groups such as senior citizens. Contrary to the episodic care provided by the biomedical model, house visits allow for the building of strong relationships between the residents and the health promoters, which will likely increase the quality of health services provided within the community. Furthermore, this approach allows the MOH to be continually informed on the state of the community to include assessing risk in order to prevent possible future epidemics [33]. Health Promoters can also be the base for organizing community-wide work parties to remove standing water during rainy season to reduce the prevalence of mosquitoes and prevent outbreaks of malaria and dengue fever.

Perhaps most important, the community health promoters should also be intimately involved in the planning, implementation, and execution of local, regional, and national healthcare plans. Since the health promoters will live in the communities in which they work, their insight into the conditions of the community, as well as the culture of the people, is crucial to developing, implementing, and continually refining plans to solve healthcare problems and provide quality services. Although a lack of participation on behalf of citizens might be a concern; providing a basic salary ( $\$ 400$ - 500) for part-time work would result in many persons desiring to earn the position of health promoter in communities such as Las Mercedes where the average family income is only around \$200. The involvement of residents will result in the empowerment of communities as the role of the administrative state will be reduced in this "horizontal" approach to healthcare. 
Ultimately, the creation and implementation of a community-based health promoter program can chip away at the dominance of the biomedical model in several important ways. First, the healthcare system can move away from an "expert-led" approach as dictated by the biomedical model to one that is participatory in nature as local communities will generate and legitimize the system rather than "government ministries or external agencies" [30]. Second, the community-based program can be a major step toward empowering communities to solve their own health problems while simultaneously reducing their reliance on government, NGO's, and other organizations that aim to intervene on their behalf. The role of the state and other organizations should not be to define the healthcare system and enforce policies and regulations, but to provide support and guidance to communities in order to develop locally-driven healthcare programs that meet the needs of individual communities. Additionally, through direct participation residents will begin to view themselves as part of the solution instead of the source of the problem. Third, the focus on health promotion and disease prevention will challenge the "popular imagination of medicine as the key to quick physical fixes and ever-extending longevity" that is pushed by the biomedical model [14]. Overall, the health promoter program can be a key element to creating a healthcare system that is proactive, responsive, and flexible in order to reduce health inequities by addressing the health the needs and problems of each individual community [34].

\section{Concluding Remarks}

The Ecuadorian government has made significant gains in the past few years in the field of healthcare. Access has been greatly increased through an expansion of infrastructure and newly designed intervention programs have drastically reduced the rate of childhood anemia and other typical diseases in Ecuador. However, the continued entrenchment of the biomedical model as the dominant narrative within healthcare is problematic. The result has been the construction of an administrative state that delivers episodic care while also developing and enforcing health policies and programs from the top-down. Although this approach has been successful at the national level, our research and fieldwork revealed major problems at the community level. Accordingly, we are calling for a state supported community-based health promoter program that would be implemented in communities such as Las Mercedes across the country. Based on the principles of health promotion, community residents would develop and execute local healthcare plans to provide quality service and prevent diseases such as malaria and dengue fever. This type of institutional arrangement will assure that practices are cemented within the regular workings of the healthcare system that not only encourage participation but require active involvement with citizens defining the direction of healthcare. If implemented, the program would not only challenge the dominance of the biomedical model, but it will also be a major step toward building a healthcare system that can deliver high quality healthcare services and address health epidemics such as the one described in Las Mercedes.

\section{References}

[1] Becker, M. (2011) Correa, Indigenous Movements, and the Writing of a New Constitution in Ecuador. Latin American Perspectives, 38, 47-62. http://dx.doi.org/10.1177/0094582X10384209

[2] Lind, A. (2012) “Revolution with a Woman’s Face”? Family Norms, Constitutional Reform, and the Politics of Redistribution in Post-Neoliberal Ecuador. Rethinking Marxism: A Journal of Economics, Culture, \& Society, 24, 536-555.

[3] Conaghan, C.M. (2008) Ecuador: Correa’s Plebiscitary Presidency. Journal of Democracy, 19, 46-60. http://dx.doi.org/10.1353/jod.2008.0026

[4] Goldman, M. (2009) La descentralización del sistema de salud del Ecuador: Un estudio comparativo de "Espacio de Decisión” y capacidad entre los sistemas municipales de salud de Quito, Guayaquil y Cuenca. http://www.flacsoandes.org/web/imagesFTP/12002.Goldman_Mateo.pdf

[5] De Paepe, P., Echeverría Tapia, R., Santacruz, E., et al. (2012) Ecuador’s Silent Health Reform. International Journal of Health Services, 2, 219-233. http://dx.doi.org/10.2190/HS.42.2.e

[6] Desarrollosocial.gob.ec (2013) Programa Acción Nutrición. http://www.desarrollosocial.gob.ec/programa-accion-nutricion/

[7] Ecuadorinmediato.com (2013) Más de 350 mil niños ecuatorianos reciben micronutrientes contra la anemia desde hoy. http://www.ecuadorinmediato.com/index.php?module=Noticias\&func=news user view\&id=196498\&umt=me1s de 350 mil nif1os ecuatorianos reciben micronutrientes contra la anemia desde hoy

[8] Ecuadorinmediato.com (2013) Sistema de Salud de Ecuador se ubica entre los 20 mejores del mundo. http://www.ecuadorinmediato.com/index.php?module=Noticias\&func=news_user_view\&id=204639\&umt=sistema_sa 
lud_ecuador_se_ubica_entre_20_mejores_del_mundo

[9] Republic of Ecuador (2013) Constitution of 2008. http://pdba.georgetown.edu/Constitutions/Ecuador/english08.html

[10] Beckerman, P. (2002) Crisis and Dollarization in Ecuador: Stability, Growth and Social Equity. World Bank, Washington DC. http://dx.doi.org/10.1596/0-8213-4837-X

[11] Sottoli, S. and Núñez, J.F. (2006) Social Investment Initiatives in Latin America: Linking Budgets, Poverty Reduction and Children's Rights. Revista Panameña de Política, 1, 151-172.

[12] Waters, W.F. (2006) Globalization and Local Response to Epidemiological Overlap in 21st Century Ecuador. Globalization and Health, 2.

[13] Cooley, S. (2008) Bringing Body to Bear in the Andes: Ethnicity, Gender, and Health in Highland Ecuador. New Directions in Medical Anthropology, 17, 132-160.

[14] Baum, F., Bégin, M., Houweling, T. and Taylor, S. (2009) Changes Not for the Fainthearted: Reorienting Health Systems toward Health Equity through Action on the Social Determinants of Health. American Journal of Public Health, 99, 1967-1974. http://dx.doi.org/10.2105/AJPH.2008.154856

[15] Wade, D.T. and Halligan, P.W. (2004) Do Biomedical Models of Illness Make for Good Healthcare Systems? British Medical Journal, 329, 1398-1401. http://dx.doi.org/10.1136/bmj.329.7479.1398

[16] Navarro, V. (2008) Neoliberalism and Its Consequences: The World Health Situation since Alma Ata. Global Social Policy, 8, 152-155. http://dx.doi.org/10.1177/14680181080080020203

[17] Tejerina, H., Soors, W., De Paepe, P., Aguilar Santacruz, E., Closon, C.M. and Unger, J.P. (2009) Socialist Government Health Policy Reforms in Bolivia and Ecuador: The Underrated Potential of Integrated Care to Tackle the Social Determinants of Health. Social Medicine in Practice, 4, 226-234.

[18] World Health Organization (WHO) (2013) Country Cooperation Strategy: At a Glance. Switzerland. http://www.who.int/countryfocus/cooperation_strategy/ccsbrief_ecu_en.pdf

[19] Alvaro, M. (2011) Ecuador Bolsters Strained Health Care System. http://online.wsj.com/article/SB10001424052748704803604576078411033873184.html

[20] Ministerio de Desarrollo Urbano y Vivienda (2013) Programa de intervención territorial e integral. http://www.habitatyvivienda.gob.ec/programa-de-intervencion-territorial-e-integral/

[21] Bloomberg.com (2013) Most Efficient Health Care: Countries. http://www.bloomberg.com/visual-data/best-and-worst/most-efficient-health-care-countries

[22] Baum, F., MacDougall, C. and Smith, D. (2006) Participatory Action Research. Journal of Epidemiology and Community Health, 60, 854-857. http://dx.doi.org/10.1136/jech.2004.028662

[23] Mundel, E. and Chapman, G.E. (2010) A Decolonizing Approach to Health Promotion in Canada: The Case of the Urban Aboriginal Community Kitchen Garden Project. Health Promotion International, 25, 166-173. http://dx.doi.org/10.1093/heapro/daq016

[24] Robertson, A. (1998) Shifting Discourses on Health in Canada: From Health Promotion to Population Health. Health Promotion International, 13, 155-166. http://dx.doi.org/10.1093/heapro/13.2.155

[25] Nylen, W.R. and Dodd, L.C. (2003) Participatory Democracy versus Elitist Democracy: Lessons from Brazil. Palgrave Macmillan, New York. http://dx.doi.org/10.1057/9781403980304

[26] Rubin, E. (2009) The Citizen Lawyer and the Administrative State. William and Mary Law Review, 50, $1335-1379$.

[27] World Health Organization (WHO) (1986) Ottawa Charter for Health Promotion. http://www.who.int/healthpromotion/conferences/previous/ottawa/en/

[28] Brown III, H.S., Stigler, M., Perry, C., Dhavan, P., Arora, M. and Reddy, K.S. (2013) The Cost-Effectiveness of a School-Based Smoking Prevention Program in India. Health Promotion International, 28, 178-186. http://dx.doi.org/10.1093/heapro/dar095

[29] Kumar, S. and Preetha, G.S. (2012) Health Promotion: An Effective Tool for Global Health. Indian Journal of Community Medicine, 37, 5-12. http://dx.doi.org/10.4103/0970-0218.94009

[30] Roberts, G. (1997) The Kadavu Health Promotion Model, Fiji. Health Promotion International, 12, 283-290. http://dx.doi.org/10.1093/heapro/12.4.283

[31] Jiang, Z., Wang, D., Yang, S., Duan, M., Bu, P., Green, A. and Zhang, X. (2011) Integrated Response toward HIV: A Health Promotion Case Study from China. Health Promotion International, 26, 196-211. http://dx.doi.org/10.1093/heapro/daq044

[32] Laverack, G. and Mohammadi, N.K. (2011) What Remains for the Future: Strengthening Community Actions to Become an Integral Part of Health Promotion Practice. Health Promotion International, 26, 258-262. 
[33] Ndiaye, S.M., Quick, L., Sanda, O. and Niandou, S. (2003) The Value of Community Participation in Disease Surveillance: A Case Study from Niger. Health Promotion International, 18, 89-98.

http://dx.doi.org/10.1093/heapro/18.2.89

[34] Baum, F., Newman, L., Biedrzycki, K. and Patterson, J. (2010) Can a Regional Government’s Social Inclusion Initiative Contribute to the Quest for Health Equity? Health Promotion International, 25, 474-482. http://dx.doi.org/10.1093/heapro/daq033 